\title{
Penerapan Metode Human Organization Technology (HOT) Fit Model Untuk Evaluasi Implementasi Pelayanan Imunisasi Balita Di Lingkungan Rt 001/07 Desa Krukut Kecamatan Limo Kota Depok
}

\author{
Muchammad Bagoes Setyawanto ${ }^{1}$, Risky Niahastuningtyas ${ }^{2}$, Sugi Hayati ${ }^{3}$
}

\begin{abstract}
Currently every organization excels in implementing information systems in order to improve quality and efficiency in business processes and services, this aims to provide a competitive added value. Evaluation of the service system needs to be done to determine the implementation of the service information system implementation which is assessed based on user satisfaction. implementation of service information system evaluation in Krukut Village using the HOT-Fit Model method. The results of the success of the Immunization Service Information System can be seen from three aspects, namely, Human, Organization and Technology, and consists of several variables, namely System User (PS), Objective (KP), Organizational Structure (SO), Organizational Environment (LO), System Quality (KS), Information Quality (KI), Service Quality (KL), and Benefits (NB).
\end{abstract}

Keywords: HOT- Fit Model, Posyandu, Information System Service.

\begin{abstract}
Intisari-Saat ini setiap organisasi dituntut untuk mengimplementasikan sistem informasi agar dapat meningkatkan kualitas dan efisiensi dalam proses bisnis maupun pelayanan, hal ini bertujuan agar dapat memberikan suatu nilai tambah berupa kompetitif unggul. Evaluasi implementasi sistem pelayanan perlu dilakukan untuk mengetahui tingkat keberhasilan implementasi sistem informasi pelayanan yang dinilai berdasarkan kepuasana pengguna. Evaluasi implementasi sistem informasi pelayanan imunisasi di Desa Krukut menggunakan metode HOT-Fit Model. Hasil evaluasi keberhasilan Sistem Infomasi Pelayanan Imunisasi dapat dilihat dari tigas aspek yaitu, Human, Organization dan Technology, dan terdiri dari beberapa variabel, yaitu variabel Pengguna Sistem (PS), Kepuasan Pengguna (KP), Strukutur Organisasi (SO), Lingkungan Organisasi (LO), Kualitas Sistem (KS), Kualitas Informasi (KI), Kualitas Layanan (KL), dan Net Benefit (NB).
\end{abstract}

Kata Kunci: HOT- Fit Model, Posyandu, Sistem Informasi Pelayanan.

1, 2, 3 Jurusan Sistem Informasi Universitas Nusa Mandiri Jakarta, Jln. Kramat Raya No. 25 Jakarta Pusat 10420 INDONESIA (telp: 021-31908575; fax: 021-31908565; e-mail: muchammadbagoes@gmail.com,

sugi3@bsi.ac.id )

\section{PENDAHULUAN}

Saat ini teknologi informasi menjadi salah satu sumber daya utama pada suatu organisasi yang memegang peranan penting untuk meningkatkan daya saing serta memberikan pelayanan yang optimal. Oleh sebab itu, setiap organisasi dituntut untuk mengimplementasikan sistem informasi agar dapat meningkatkan kualitas dan efisiensi dalam proses bisnis maupun pelayanan, hal ini bertujuan agar dapat memberikan suatu nilai tambah berupa kompetitif unggul, tidak terkecuali pada organisasi pemerintahan yang pada dasarnya perkembangan teknologi Informasi (TI) yang terjadi pada saat ini sangat berperan dalam penyelenggaraan organisasi pemerintahan (Mulyadi, Dedy, 2019), (Awalludin, Dudi, 2020), (Kristania, Yustina, 2015).

Seperti yang dijelaskan pada jurnal yang terkait dalam penelitian ini, Sistem Informasi Puskesmas ialah suatu tatanan yang menyediakan informasi untuk membantu proses pengambilan keputusan dalam melaksanakan manajemen puskesmas untuk mencapai sasaran kegiatannya. Pencatatan adalah serangkaian kegiatan untuk mendokumentasikan hasil pengamatan, pengukuran atau perhitungan pada setiap langkah upaya kesehatan yang dilaksanakan Puskesmas (Permenkes RI, No. 31 Tahun 2019) (Hariyanto, Muhadi, 2020).

Desa Krukut telah menerapkan sistem informasi pelayanan yang bernama Sistem Informasi Pelayanan Imunisasi, sistem ini diterapkan selama satu bulan. Sistem Informasi Pelayanan Imunisai adalah sebuah perangkat lunak yang digunakan untuk menyajikan suatu informasi dan menata pengelolaan dokumen yang berhubungan dengan pelayanan imunisasi. Dengan penggunaan perangkat lunak seperti ini diharapkan kegiatan pelayanan imunisasi dapat dikelola dengan baik dan informasi yang diperlukan dapat diperoleh dengan mudah dan cepat (Monalisa, S, 2018).

Setelah diterapkannya sistem informasi pelayanan ini terdapat beberapa kendala yaitu kendala dari faktor pengguna berupa kurangnya pemahaman dan ketelitian dalam menginput dan mencocokkan data balita dan ibu hamil yang menyebabkan data tersebut terduplikasi, akibat yang ditimbulkan dari permasalahan ini adalah penerapan SIPI menjadi tidak tepat sasaran yang berakibat pada kualitas informasi yang disampaikan, sehingga mempengaruhi kepuasan pengguna. Adapun kendala dari faktor organisasi adalah tidak meratanya pelatihan dan manual book yang diberikan kepada pengguna, hal ini mengakibatkan kurangnya pemahaman serta minat pengguna dalam menggunakan aplikasi SIPI. Kendala faktor dari teknologi adalah terdapatnya NIK atau ID yang sama, yang disebabkan oleh 
sistem yang tidak mempunyai primary key terhadap data ibu hamil dan balita (Cahyani, Anggita Pramesti Putri, 2020). Hal ini akan mengakibatkan kualitas informasi yang akan diterima oleh pengguna menjadi tidak sesuai. Selain itu terdapat kerusakan pada sistem yang menampilkan source code ini terjadi ketika admin akan melakukan pengolahan data imunisasi, hal ini berdampak pada kepuasan pengguna dalam menggunakan SIPI.

\section{BAHAN DAN METODE}

Penelitian ini dilakukan untuk mengevaluasi aspek Human Organization Technology (HOT-Fit Model) yang mempengaruhi tingkat keberhasilan terhadap implementasi aplikasi Sistem Informasi Pelayanan Imunisasi (SIPI) Posyandu. Menurut Evrilyan (2017) HOT Fit merupakan salah satu kerangka teori yang dipakai untuk mengevaluasi sistem informasi. Model ini merupakan kombinasi dari model kesuksesan sistem infomasi dari Delobe dan Mclean dan IT Organization Fit Model dari Morton (Hariyanto, Muhadi, 2020).

Implementasi aplikasi ini diukur berdasarkan dari empat komponen yaitu komponen manusia (Human), komponen organisasi (Organization), komponen teknologi (Technology), dan komponen manfaat (Net Benefit) (Hariyanto, Muhadi, 2020). Berikut adalah komponen penting dari Metode HOTFit Model :

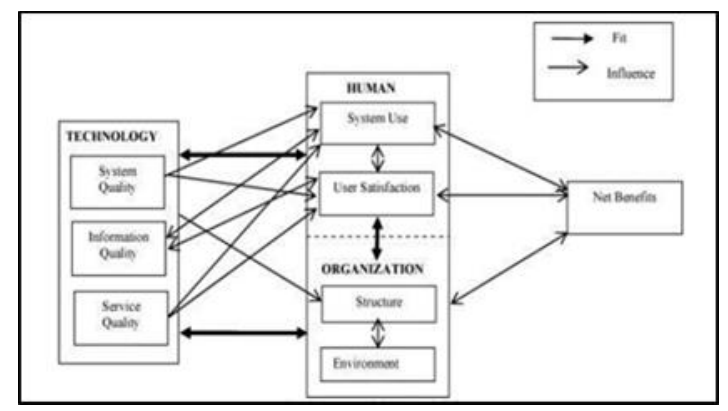

Gambar I. HOT Model

Sumber : (Yusof, Maryati Mohd, 2006)

"Penelitian adalah usaha untuk menemukan, mengembangkan dan menguji kebenaran suatu pengetahuan, usaha mana dilakukan dengan menggunakan metode ilmiah" (Mulyadi, Dedy, 2019). Untuk mendapatkan hasil penelitian yang maksimal, maka diperlukan desain penelitian untuk menunjang dan memberikan hasil penelitian yang baik dan sistematik. Desain penelitian merupakan proses yang dibutuhkan dalam perencanaan dan pelaksanaan penelitian yang membantu penelitian dalam pengumpulan data dan menganalisis data.

Pada penelitian ini terdiri dari 5 tahap, yaitu :

1. Tahap Pendahuluan

Pada tahap ini penulis menentukan objek penelitian.

Penulis telah memutuskan bahwa objek pada penelitian ini adalah Evaluasi Implementasi Pelayanan Sistem Imunisasi Posyandu.

2. Tahap Perencanaan

Evaluasi Implementasi Pelayanan Sistem Imunisasi Posyandu bertujuan untuk mengetahui bagaimana manfaat yang didapat dan ditinjau dari segi pengguna, organisasi, dan teknologi dengan menggunakan metode HOT-Fit.

3. Tahap Pengumpulan Data

Pada tahap ini penulis menggunakan metode observasi, wawancara dan angket/kuesioner dengan pengelola pada sistem Posyandu.

4. Tahap Pengolahan Data

Pengolahan data yang digunakan penulis menggunakan teknik analisis statistik SEM (Structural Equation Model) dengan tools berupa aplikasi SmartPLS 3.0.

5. Analisis Data

Analisis data yang dilakukan adalah menganalisis hipotesis dan menganisis secara deskriptif kuantitatif data yang didapatkan dari hasil penyebaran angket/kuesioner.

Pada rancangan model penelitian ini terdapat variabelvariabel laten atau konstruk yang akan diteliti yaitu pengguna sistem (sistem use), kepuasan pengguna (user statisfaction), struktur organisasi (structure), lingkungan organisasi (environment), kualitas sistem (sistem quality), kualitas informasi (information quality), kualitas layanan (service quality), manfaat (net benefit). Model penelitian yang akan digunakan dari HOT-Fit Model seperti pada gambar III.2. menjelaskan bahwa Net Benefit (Y1) dipengaruhi oleh Human (X1), Organization (X2), Technology (X3).

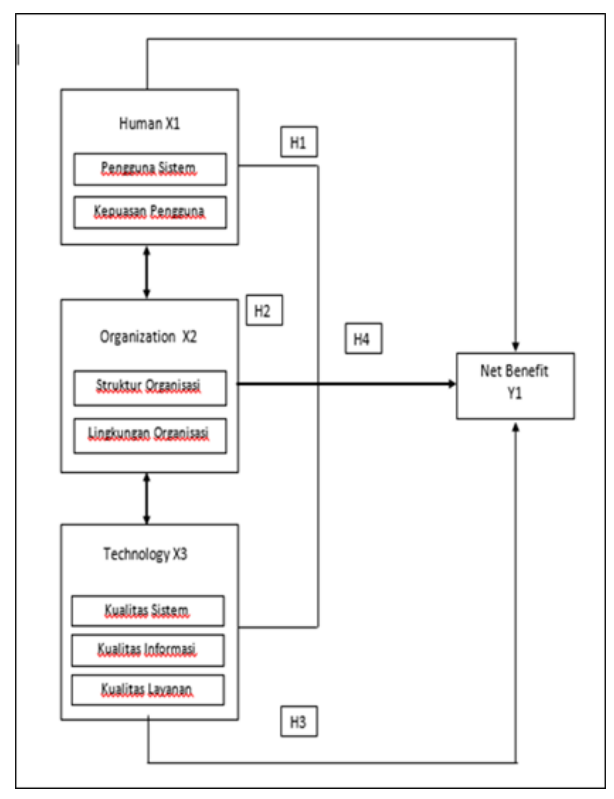

Gambar II. Modifikasi Model HOT-Fit 
Pernyataan penelitian berdasarkan metode HOT-Fit Model yang digunakan seperti pada Gambar III.

\begin{tabular}{|c|c|c|c|}
\hline Variabel & Konstruk & Indikator & Kode \\
\hline \multirow[t]{7}{*}{ Human (X1) } & \multirow[t]{4}{*}{$\begin{array}{l}\text { Pengguna } \\
\text { Sistem }\end{array}$} & $\begin{array}{l}\text { 1. Penggunaan } \\
\text { SIPI } \\
\text { mempercepat } \\
\text { proses } \\
\text { pencarian } \\
\text { informasi }\end{array}$ & PS1 \\
\hline & & $\begin{array}{l}\text { 2. Pengguna SIPI } \\
\text { dapat } \\
\text { membantu } \\
\text { tugas sehari- } \\
\text { hari }\end{array}$ & PS2 \\
\hline & & $\begin{array}{ll}3 . & \text { Penggunaan } \\
& \text { SIPI } \\
& \text { membantu } \\
\text { dalam } \\
\text { mengambil } \\
\text { keputusan } \\
\end{array}$ & PS3 \\
\hline & & $\begin{array}{ll}\text { 4. } & \text { Penggunaan } \\
\text { SIPI } \\
\text { mempermudah } \\
\text { pekerjaan }\end{array}$ & PS4 \\
\hline & \multirow[t]{3}{*}{$\begin{array}{l}\text { Kepuasan } \\
\text { pengguna }\end{array}$} & $\begin{array}{l}\text { 1. Informasi } \\
\text { yang disajikan } \\
\text { tepat waktu } \\
\text { atau up to } \\
\text { date. }\end{array}$ & KP1 \\
\hline & & $\begin{array}{ll}\text { 2. } & \text { Isi yang } \\
& \text { disajikan } \\
& \text { sesuai dengan } \\
& \text { kebutuhan } \\
& \text { pengguna. }\end{array}$ & KP2 \\
\hline & & $\begin{array}{ll}\text { 3. } & \text { Sistem } \\
& \text { Informasi } \\
\text { Pelayanan } \\
\text { menyajikan } \\
\text { fitur-fitur yang } \\
\text { mudah untuk } \\
\text { digunakan } \\
\text { pengguna. } \\
\end{array}$ & KP3 \\
\hline \multirow[t]{3}{*}{$\begin{array}{l}\text { Organization } \\
\text { (X2) }\end{array}$} & \multirow[t]{3}{*}{$\begin{array}{l}\text { Struktur } \\
\text { Organisasi }\end{array}$} & $\begin{array}{l}\text { 1. Organisasi } \\
\text { mempertimba } \\
\text { ngkan latar } \\
\text { belakang } \\
\text { pendidikan } \\
\text { dalam } \\
\text { pengelolaan } \\
\text { sistem. } \\
\end{array}$ & SO1 \\
\hline & & $\begin{array}{l}\text { 2. Organisasi } \\
\text { memberikan } \\
\text { pelatihan } \\
\text { kepada } \\
\text { pengguna } \\
\text { sistem } \\
\text { dianggap perlu } \\
\text { bagi pengguna } \\
\text { sistem. }\end{array}$ & $\mathrm{SO} 2$ \\
\hline & & 3. Organisasi & S03 \\
\hline
\end{tabular}

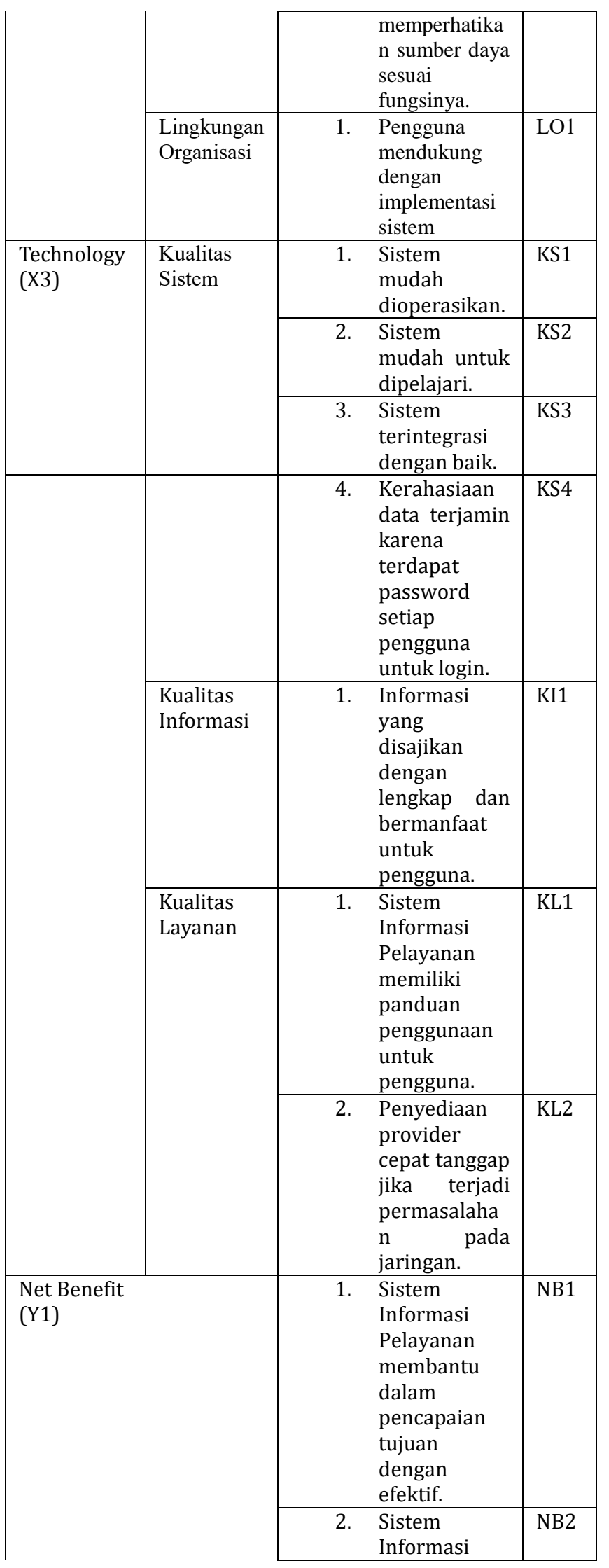




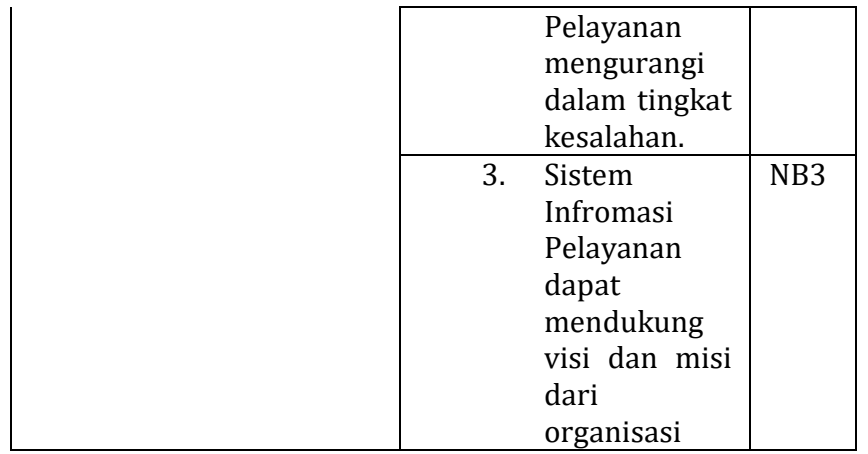

Table I. Pertanyaan kuesioner

Sumber : (Lestariningsih, Tri, 2020)

Hipotesis dalam penelitian ini penulis dapat menjelaskan dibawah:

1. Pengguna system secara signifikan dipengaruhi oleh kualitas system dalam penerapan system infromasi pelayanan $(\mathrm{H} 1)$

2. Kepuasan pengguna dipengaruhi secara signifikan oleh kualitas system $(\mathrm{H} 2)$.

3. Penggunaan system secara signifikan dipengaruhi kualitas informasi (H3.

4. Kepuasan pengguna secara signifikan dipengaruhi oleh kualitas informasi (H4).

5. Penggunaan sisitem secara signifikan dipengaruhi oleh kualitas layanan (H5).

6. Kepuasan pengguna secara signifikan dipengaruhi oleh kualitas layanan (H6).

7. Pengguna system secara signifikan dipengaruhi oleh kepuasan pengguna $(\mathrm{H} 7)$.

8. Lingkungan organisasi secara signifikan dipengaruhi oleh struktur organisasi (H8).

9. Manfaat secara signifikan dipengaruhi oleh pengguna system (H9).

10. Manfaat secara signifikan dipengaruhi oleh kepuasan pengguna (H10).

11. Manfaat secara signifikan dipengaruhi oleh struktur organisasi (H11).

12. Manfaat secara signifikan dipengaruhi oleh lingkungan organisasi (H12).

\section{HASIL DAN PEMBAHASAN}

\section{Analisis Sistem}

Responden pada penelitian ini adalah orang tua yang terdaftar di Posyandu atau pengguna sistem informasi pelayanan imunisasi di Posyandu yang berjumlahkan 30 orang. Responden akan menilai pernyataan dengan skala likert berdasarkan konsistensi terhadap sistem informasi pelayanan imunisasi pada posyandu dengan berjumlah 22 pernyataan. Pernyataan ini mencakup pembahasan dari variabel HOT dan Net Benefit. Teknik untuk menyebarkan dan mengisi angket/kuesioner menggunakan tool Google Form. Berikut adalah instrumen kuesioner yang akan digunakan untuk mengukur kualitas dari Sistem Informasi Pelayanan Imunisasi (SIPI) pada Posyandu. Pada tabel III.3. Instrumen Kuesioner Evaluasi Sistem merupakan penjelasan setiap sub karakter yang akan dinilai oleh responden, sesuai dengan indikatorindikator dari sistem yang di evaluasi.

\begin{tabular}{|c|c|c|}
\hline Karakter & Sub Karakter & Jawaban \\
\hline $\begin{array}{l}\text { Pengguna } \\
\text { Sistem }\end{array}$ & $\begin{array}{l}\text { PS1 = Penggunaan SIPI } \\
\text { mempercepat proses } \\
\text { pencarian informasi. } \\
\text { PS2 = Penggunaan SIPI } \\
\text { dapat membantu tugas } \\
\text { sehari-hari. } \\
\text { PS3 = Penggunaan SIPI } \\
\text { membantu dalam } \\
\text { mengambil keputusan. } \\
\text { PS4 = Penggunaan SIPI } \\
\text { mempermudah } \\
\text { perkerjaan. }\end{array}$ & $\begin{array}{l}\text { 1. Sangat Setuju (5) } \\
\text { 2. Setuju (4) } \\
\text { 3. Netral (3) } \\
\text { 4. Tidak Setuju (2) } \\
\text { 5. Sangat Tidak } \\
\text { Setuju (1) }\end{array}$ \\
\hline $\begin{array}{l}\text { Kepuasan } \\
\text { Pengguna }\end{array}$ & $\begin{array}{l}\text { KP1 = Informasi yang } \\
\text { disajikan tepat waktu } \\
\text { atau up to date. } \\
\text { KP2 = Isi yang } \\
\text { disajikan sesuai dengan } \\
\text { kebutuhan pengguna. } \\
\text { KP3 = System } \\
\text { Informasi Pelayanan } \\
\text { menyajikan fitur-fitur } \\
\text { yang mudah untuk } \\
\text { digunakan pengguna. }\end{array}$ & $\begin{array}{l}\text { 1. Sangat Setuju (5) } \\
\text { 2. Setuju (4) } \\
\text { 3. Netral (3) } \\
\text { 4. Tidak Setuju (2) } \\
\text { 5. Sangat Tidak } \\
\text { Setuju (1) }\end{array}$ \\
\hline $\begin{array}{l}\text { Struktur } \\
\text { Organisasi }\end{array}$ & $\begin{array}{l}\text { SO1 = Organisasi } \\
\text { mempertimbangkan } \\
\text { latar belakang } \\
\text { pendidikan dalam } \\
\text { pengelolaan sistem. } \\
\mathrm{SO} 2 \text { = Organisasi } \\
\text { memberikan pelatihan } \\
\text { kepada pengguna } \\
\text { sistem dianggap perlu } \\
\text { bagi pengguna sistem } \\
\text { SO3 = Organisasi } \\
\text { memperhatikan sumber } \\
\text { daya sesuai fungsinya. }\end{array}$ & $\begin{array}{l}\text { 1. Sangat Setuju (5) } \\
\text { 2. Setuju (4) } \\
\text { 3. Netral (3) } \\
\text { 4. Tidak Setuju (2) } \\
\text { 5. Sangat Tidak } \\
\text { Setuju (1) }\end{array}$ \\
\hline $\begin{array}{l}\text { Lingkung } \\
\text { an } \\
\text { Organisasi }\end{array}$ & $\begin{array}{l}\text { LO1 = Pengguna } \\
\text { mendukung dengan } \\
\text { implementasi sistem. }\end{array}$ & $\begin{array}{l}\text { 1. Sangat Setuju (5) } \\
\text { 2. Setuju (4) } \\
\text { 3. Netral (3) } \\
\text { 4. Tidak Setuju (2) } \\
\text { 5. Sangat Tidak } \\
\text { Setuju (1) }\end{array}$ \\
\hline $\begin{array}{l}\text { Kualitas } \\
\text { Sistem }\end{array}$ & $\begin{array}{l}\text { KS1 = Sistem mudah } \\
\text { dioperasikan. } \\
\text { KS2 = Sistem mudah } \\
\text { untuk dipelajari. } \\
\text { KS3 = Sistem } \\
\text { terintegrasi dengan } \\
\text { baik. } \\
\text { KS4 = Kerahasiaan data } \\
\text { terjamin karena } \\
\text { terdapat password }\end{array}$ & $\begin{array}{l}\text { 1. Sangat Setuju (5) } \\
\text { 2. Setuju (4) } \\
\text { 3. Netral (3) } \\
\text { 4. Tidak Setuju (2) } \\
\text { 5. Sangat Tidak } \\
\text { Setuju (1) }\end{array}$ \\
\hline
\end{tabular}




\begin{tabular}{|c|c|c|}
\hline & $\begin{array}{l}\text { setiap pengguna untuk } \\
\text { login }\end{array}$ & \\
\hline $\begin{array}{l}\text { Kualitas } \\
\text { Informasi }\end{array}$ & $\begin{array}{l}\text { KI1 = Informasi yang } \\
\text { disajikan dengan } \\
\text { lengkap dan bermanfaat } \\
\text { untuk pengguna. }\end{array}$ & $\begin{array}{l}\text { 1. Sangat Setuju (5) } \\
\text { 2. Setuju (4) } \\
\text { 3. Netral (3) } \\
\text { 4. Tidak Setuju (2) } \\
\text { 5. Sangat Tidak } \\
\text { Setuju (1) }\end{array}$ \\
\hline $\begin{array}{l}\text { Kualitas } \\
\text { Layanan }\end{array}$ & $\begin{array}{l}\text { KL1 = Sistem } \\
\text { Informasi Pelayanan } \\
\text { memiliki panduan } \\
\text { pengguaan untuk } \\
\text { pengguna. } \\
\text { KL2 = Penyediaan } \\
\text { provider cepat tanggap } \\
\text { jika terjadi } \\
\text { permasalahan pada } \\
\text { jaringan. }\end{array}$ & $\begin{array}{l}\text { 1. Sangat Setuju (5) } \\
\text { 2. Setuju (4) } \\
\text { 3. Netral (3) } \\
\text { 4. Tidak Setuju (2) } \\
\text { 5. Sangat Tidak } \\
\text { Setuju (1) }\end{array}$ \\
\hline $\begin{array}{l}\text { Net } \\
\text { Benefit } \\
(\mathrm{Y} 1)\end{array}$ & $\begin{array}{l}\text { NB1 = Sistem } \\
\text { informasi pelayanan } \\
\text { membantu dalam } \\
\text { pencapaian tujuan } \\
\text { dengan efektif } \\
\text { NB2 = System } \\
\text { informasi pelayanan } \\
\text { mengurangi dalam } \\
\text { tingkat kesalahan } \\
\text { NB3 = System } \\
\text { informasi pelayanan } \\
\text { dapat mendukung visi } \\
\text { dan misi dari oranisasi }\end{array}$ & $\begin{array}{l}\text { 1. Sangat Setuju (5) } \\
\text { 2. Setuju (4) } \\
\text { 3. Netral (3) } \\
\text { 4. Tidak Setuju (2) } \\
\text { 5. Sangat Tidak } \\
\text { Setuju (1) }\end{array}$ \\
\hline
\end{tabular}

Tabel II. Instrumen Kuesioner Evaluasi Sistem

Sumber : (Ayuardini, Marisha, 2019)

Teknik pengolahan data menggunakan teknik analisis stastistik SEM-SmartPLS 3.0. Analisis SEM-SmartPLS terdapat dua model yaitu model pengukuran dan model struktural. Model pengukuran menggambarkan bagaimana variabel manifest mempresentasikan variabel laten untuk diukur. Sedangkan model struktural menggambarkan kekuatan estimasi antar variabel laten (Derajat, Pemodelan, 2015).

\section{A. Struktural Model}

Pengujian strukutural model untuk menguji perubahan variable dependent terhadap perubahan indikator. Pada gambar IV.1 merupakan model struktural dalam penelitian ini.

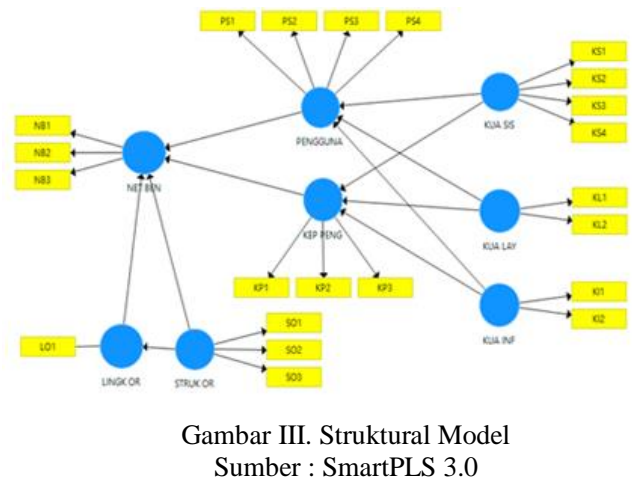

Gambar IV.1 menunjukan bahwa evaluasi implementasi Sistem Informasi Pelayanan Imunisasi (SIPI) menggunakan konstruk Pengguna Sistem (sistem use) dengan 4 indikator yaitu PS1, PS2, PS3, dan PS4. Kepusaan Pengguna dengan 3 indikator yaitu KP1, KP2, dan KP3. Kualitas Sistem (sistm quality) dengan 4 indikator yaitu KS1, KS2, KS3, dan KS4. Kualitas Informasi (information quality) dengan 2 indikator KI1 dan KI2. Konstruk Kualitas Layanan (service quality) dengan 2 indikator yaitu KL1 dan KL2. Konstruk Struktur Organisasi (organisasi structure) dengan 3 indikator yaitu SO1, $\mathrm{SO} 2$, dan SO3. Konstruk Lingkungan Organisasi (environment) dengan 1 indikator yaitu LO1, untuk Manfaat (net benefit) diukur dengan 3 indikator yaitu NB1, NB2, dan NB3.

\section{B. Nilai Reliability}

Menurut A. Bayu dalam jurnal Tri Lestariningsih variabel penelitian dapat dikatakan valid jika nilai dari realiability komposit dan cronbach alpha >0,7 (Yusof, Maryati Mohd, 2006)

\begin{tabular}{|l|l|l|}
\hline $\begin{array}{l}\text { Variabel } \\
\text { Laten }\end{array}$ & $\begin{array}{l}\text { Cronbach } \\
\text { Alpha }\end{array}$ & $\begin{array}{l}\text { Composite } \\
\text { Reliability }\end{array}$ \\
\hline KP & 0,759 & 0,862 \\
\hline KI & 0,868 & 0,938 \\
\hline KL & 0,636 & 0,845 \\
\hline KS & 0,850 & 0,899 \\
\hline LO & 1,000 & 1,000 \\
\hline NB & 0,807 & 0,887 \\
\hline PS & 0,819 & 0,881 \\
\hline SO & 0,681 & 0,821 \\
\hline
\end{tabular}

Tabel III. Nilai Reliability Sumber : SmartPLS 3.0

Nilai R-Square NB sebesar 0,59, maka variabel NB yang merupakan variabel dependent (terikat) dipengaruhi beberapa variabel independent (bebas) yaitu KI,KS, dan KL dengan presentasi 59\% dan memiliki pengaruh "sedang" sedangkan $41 \%$ merupakan pengaruh dari variabel selain variabel dalam penelitian. Nilai R-Square dari LO 0,28 yang artinya bahwa SO dipengaruhi variabel LO besar presentasinya yaitu $28 \%$ hal ini menunjukan pengaruh "sedang. Nilai R-Square PS variabel 0,38 yang berarti PS dipengaruhi beberapa variabel sebesar $38 \%$ yaitu KI, KS, dan KL dan dapat disimpulkan bahwa memiliki pengaruh yang "sedang". Nilai R-Square untuk variabel KP sebesar 0,73 yang artinya variabel PS, LO, NB dapat berpengaruh sebesar $73 \%$ atau berpengaruh "baik" terhadap variabel KP. 
C. Nilai Variabel

\begin{tabular}{|l|l|l|l|}
\hline Hipotesis & Variabel & $\begin{array}{l}\text { Original } \\
\text { Sample } \\
(\mathrm{O})\end{array}$ & $\begin{array}{l}\text { T-Statistics } \\
(|\mathrm{O} / \mathrm{STDEV}|)\end{array}$ \\
\hline H1 & $\begin{array}{l}\text { KEP PENG -> } \\
\text { NET BEN }\end{array}$ & 0.708 & 4.009 \\
\hline H2 & $\begin{array}{l}\text { KUA INF -> } \\
\text { KEP PENG }\end{array}$ & 0.862 & 6.979 \\
\hline H3 & $\begin{array}{l}\text { KUA INF -> } \\
\text { PENG SIS }\end{array}$ & 0.272 & 0.979 \\
\hline H4 & $\begin{array}{l}\text { KUA LAY -> } \\
\text { KEP PENG }\end{array}$ & -0.450 & 2.361 \\
\hline H5 & $\begin{array}{l}\text { KUA LAY -> } \\
\text { PENG SIS }\end{array}$ & 0.116 & 0.437 \\
\hline H6 & $\begin{array}{l}\text { KUA SIS -> } \\
\text { KEP PENG }\end{array}$ & 0.463 & 2.779 \\
\hline H7 & $\begin{array}{l}\text { KUA SIS -> } \\
\text { PENG SIS }\end{array}$ & 0.323 & 1.374 \\
\hline H8 & $\begin{array}{l}\text { LINGK OR - } \\
>\text { NET BEN }\end{array}$ & -0.004 & 0.030 \\
\hline H9 & $\begin{array}{l}\text { PENG SIS -> } \\
\text { NET BEN }\end{array}$ & 0.001 & 0.005 \\
\hline H10 & $\begin{array}{l}\text { STRUK OR - } \\
>\text { LINGK OR }\end{array}$ & 0.534 & 2.951 \\
\hline H11 & $\begin{array}{l}\text { STRUK OR - } \\
>\text { NET BEN }\end{array}$ & 0.190 & 1.112 \\
\hline
\end{tabular}

Tabel IV. Nilai Variabel

Sumber : SmartPLS 3.0

\section{Potensi Hasil}

Hipotesis pada tabel diatas terdiri dari 11 hipotesis. Berikut ialah penjelasannya:

1. Hasil pengujian hipotesis H1 hubungan antara Kep Peng dengan Net Ben adalah signifikan dengan T-statistik sebesar 4.009 dimana nilai original sempel adalah positif yaitu sebesar 0.708 menunjukan bahwa hubungan antara Kep Peng dengan Net Ben adalah positif. Dengan demikian hipotesis H1 menyatakan bahwa "Kepuasan Pengguna" berpengaruh terhadap "Net Benefit" yaitu diterima.

2. Hasil pengujian hipotesis $\mathrm{H} 2$ hubungan antara Kua Inf dengan Kep Peng adalah signifikan dengan T-statistik sebesar 6.979 dimana nilai original sampel adalah positif yaitu sebesar 0.862 menunjukan bahwa hubungan antara Kua Inf dengan Kep Peng adalah positif. Dengan demikian H2 menyatakan bahwa "Kualitas Informasi" berpengaruh terhadap "Kepuasan Pengguna" yaitu diterima.

3. Hasil pengujian hipotesis H3 hubungan antara Kua Inf dengan Peng Sis adalah signifikan dengan T-statistik sebesar 0.979 dimana nilai original sampel adalah positif yaitu sebesar 0.272 menunjukan bahwa hubungan antara kua inf dengan peng sis adalah positif. Dengan demikian H3 menyatakan bahwa "Kualitas Informasi" berpengaruh terhadap "Pengguna Sistem" yaitu diterima.

4. Hasil pengujian hipotesis H4 hubungan antara Kua Lay dengan Kep Peng adalah signifikan dengan T-statistik sebesar 2.361 dimana nilai original sampel adalah negatif yaitu sebesar -0.450 menunjukan bahwa hubungan antara Kua Lay dengan Kep Peng adalah negatif. Dengan demikian H4 menyatakan bahwa "Kualitas Layanan" berpengaruh terhadap "Kepuasan Pengguna" yaitu ditolak.

5. Hasil pengujian hipotesis H5 hubungan antara Kua Lay dengan Peng Sis adalah signifikan dengan T-statistik sebesar 0.437 dimana nilai original sampel adalah positif yaitu sebesar 0.116 menunjukan bahwa hubungan antara Kua Lay dengan Peng Sis adalah postitif. Dengan demikian H5 menyatakan bahwa "Kualitas Layanan" berpengaruh terhadap "Pengguna Sistem" yaitu diterima.

6. Hasil pengujian hipotesis H6 hubungan antara Kua Sis dengan Kep Peng adalah signifikan dengan T-statistik sebesar 2.779 dimana nilai original sampel adalah positif yaitu sebesar 0.463 menunjukan bahwa hubungan antara Kua Sis dengan Kep Peng adalah postitif. Dengan demikian H6 menyatakan bahwa "Kualitas Sistem" berpengaruh terhadap "Kepuasan Pengguna" yaitu diterima.

7. Hasil pengujian hipotesis H7 hubungan antara Kua Sis dengan Peng Sis adalah signifikan dengan T-statistik sebesar 1.374 dimana nilai original sampel adalah positif yaitu sebesar 0.323 menunjukan bahwa hubungan antara Kua Sis dengan Peng Sis adalah postitif. Dengan demikian H7 menyatakan bahwa "Kualitas Sistem" berpengaruh terhadap "Pengguna Sistem" yaitu diterima.

8. Hasil pengujian hipotesis $\mathrm{H} 8$ hubungan antara Link Or dengan Net Ben adalah signifikan dengan T-statistik sebesar 0.030 dimana nilai original sampel adalah negatif yaitu sebesar -0.004 menunjukan bahwa hubungan antara Link Or dengan Net Ben adalah negatif. Dengan demikian H8 menyatakan bahwa "Lingkungan Organisasi" berpengaruh terhadap "Net Benefit" yaitu ditolak.

9. Hasil pengujian hipotesis H9 hubungan Peng Sis dengan Net Ben adalah signifikan dengan T-statistik sebesar 0.005 dimana nilai original sampel adalah positif yaitu sebesar 0.001 menunjukan bahwa hubungan antara Peng Sis dengan Net Ben adalah postitif. Dengan demikian H9 menyatakan bahwa "Pengguna Sistem" berpengaruh terhadap "Net Benefit" yaitu diterima.

10. Hasil pengujian hipotesis H10 hubungan Struk Or dengan Link Or adalah signifikan dengan T-statistik sebesar 2.951 dimana nilai original sampel adalah positif yaitu sebesar 0.534 menunjukan bahwa hubungan antara Struk Or dengan Link Or adalah postitif. Dengan demikian H10 menyatakan bahwa "Struktur Organisasi" berpengaruh terhadap "Lingkungan Orgnanisasi" yaitu diterima.

11. Hasil pengujian hipotesis H11 hubungan Struk Or dengan Net Ben adalah signifikan dengan T-statistik 
sebesar 1.112 dimana nilai original sampel adalah positif yaitu sebesar 0.190 menunjukan bahwa hubungan antara Struk Or dengan Net Ben adalah postitif. Dengan demikian H11 menyatakan bahwa "Struktur Organisasi" berpengaruh terhadap "Net Benefit" yaitu diterima.

\section{GAMBAR PROGRAM}

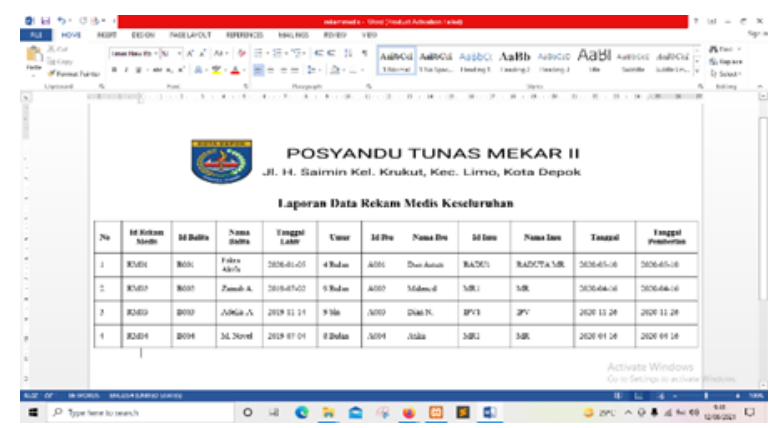

Gambar IV. Tampilan Login

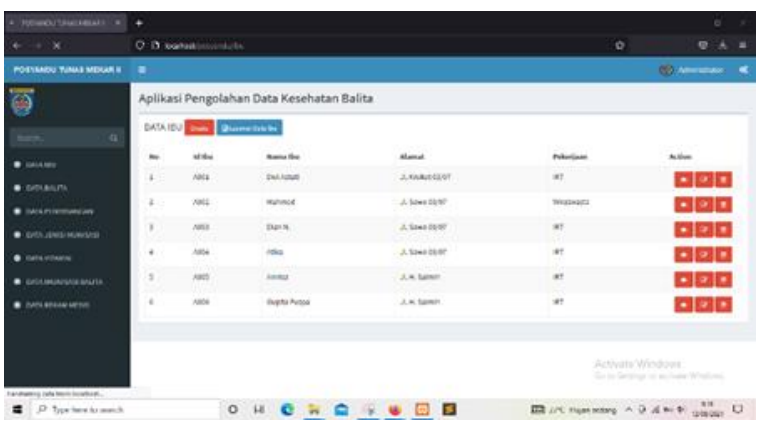

Gambar V. Tampilan data ibu

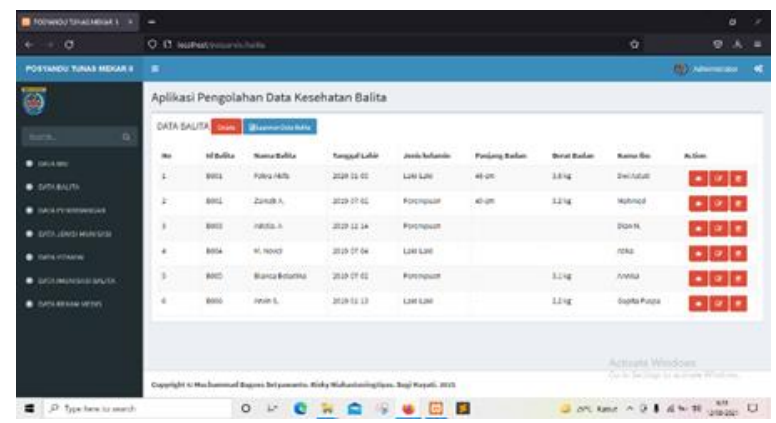

Gambar VI. Tampilan data balita

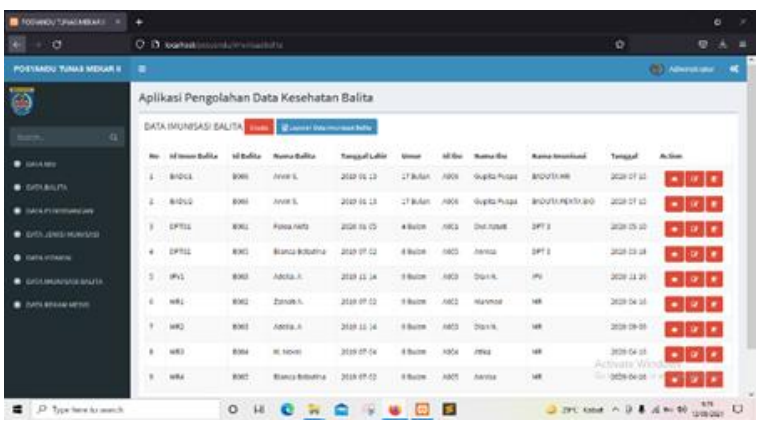

Gambar VII. Tampilan data imunisasi

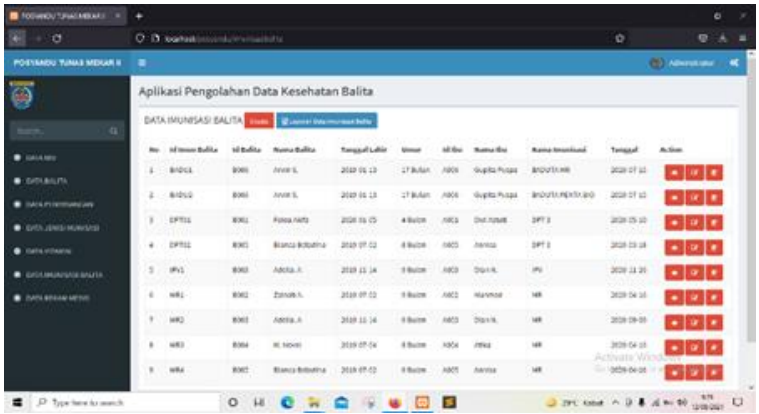

Gambar VIII. Tampilan laporan rekam medis posyandu

\section{KESIMPULAN}

Evaluasi implementasi dari Sistem Informasi Pelayanan Posyandu Imunisasi dengan menggunakan metode HOT-Fit Model dapat disimpulkan berdasarkan tiga aspek dari pandangan pengguna. Pandangan pengguna terhadap aspek teknologi yaitu variable KS, KL dan variable KI yang memiliki pengaruh positif terhadap PS dan KP. KS, KL dan KI juga berpengaruh positif terhadap NB. Pandangan pengguna terhadap aspek pengguna, dimana pengguna itu manusia sendiri, dapat dilihat bahwa variable NB mempunyai pengaruh positif terhadap PS dan KP, variable KP mempunyai pengaruh positif terhadap NB. Pengguna terhadap aspek organisasi yaitu terlihat dari variable SO berpengaruh positif terhadap variable LO. Variable NB merupakan indikator keberhasilan, dimana variabel NB mempunyai pengaruh positif terhadap manfaat dari penerapan aplikasi, dan PS, KP, SO, dan LO mempunyai pengaruh posistif terhadap variabel NB. 


\section{REFERENSI}

[1] Mulyadi, Dedy, "Penerapan Metode Human Organization Technology (HOT-Fit Model) untuk Evaluasi Implementasi Aplikasi Sistem Informasi Persediaan (SIDIA) di Lingkungan Pemerintah Kota Bogor," Teknois : Jurnal Ilmiah Teknologi Informasi dan Sains, vol. 7, no. 2, pp. 1-12, 2019.

[2] Awalludin, Dudi, "Perancangan Sistem Informasi Pelayanan Kesehatan UPTD Puskesmas XYZ," Jurnal Manajemen Informatika (JAMIKA), vol. 10, no. 2, pp. 187-201, 2020.

[3] Kristania, Yustina, "Perancangan Sistem Informasi Pelayanan Antenatal Terpadu," Jurnal Mkmi, vol. 7, no. JURNAL MKMI, September 2015, pp. 189-196, 2015.

[4] Cahyani, Anggita Pramesti Putri, "Evaluasi Penerapan Sistem Informasi Manajemen Puskesmas (Simpus) Dengan Metode Hot-Fit Di Puskesmas Gatak," Jurnal Manajemen Informasi dan Administrasi Kesehatan (JMIAK), vol. 3, no. 2, pp. 20-27, 2020.

[5] Hariyanto, Muhadi, "Perancangan Sistem Informasi Posyandu Lansia RW 02 Kampung Jembatan Penggilingan Jakarta Timur," Inti Nusa Mandiri, vol. 14 no. 2, pp. 133-138, 2020.

[6] Monalisa, S, "Analisis Kesuksesan Penerapan Sistem Administrasi Akademik Menggunakan Human Organization Technology Fit Model," Jurnal Ilmiah Rekayasa dan Manajemen Sistem Informasi, vol. 4, no. 1, pp. 36-41, 2018.

[7] Yusof, Maryati Mohd, "Towards a framework for Health Information System Evaluation, School of Information System.," Proceedings of The 39th Hawaii International Conference on System Sciences, vol. 00 no. C, pp. 1-10, 2006.

[8] Lestariningsih, Tri, "Evaluasi Implementasi E-learning dengan Metode Hot Fit Model," Innovation in Research of Informatics (INNOVATICS), vol. 2, no. 1, pp. 22-27, 2020.

[9] Ayuardini, Marisha, "Implementasi Metode Hot Fit pada Evaluasi Tingkat Kesuksesan Sistem Pengisian KRS Terkomputerisasi," Faktor Exacta, vol. 12, no. 2 pp. 122-131, 2019.

[10] Derajat, Pemodelan, "Structural Equation ModelingPartial Least Square," vol. 4, no. 2, pp. 4-9, 2015.

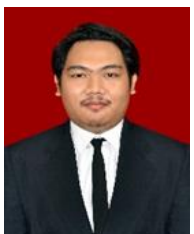

Muchammad Bagoes Setyawanto. Jakarta, 26 Agustus 1999. Mahasiswa Universitas Nusa Mandiri Jakarta yang merupakan lulusan Ahli Madya Komputer dari Program Studi Sistem Informasi Universitas Bina Sarana Informatika Jakarta.

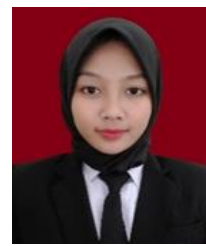

Risky Niahastuningtiyas. Yogyakarta, 14 Maret 2000. Mahasiswi Universitas Nusa Mandiri Jakarta yang merupakan lulusan Ahli Madya Komputer dari Program Studi Sistem Informasi Universitas Bina Sarana Informatika Jakarta.

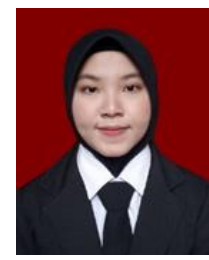

Sugi Hayati. Bogor, 29 April 1998. Mahasiswi Universitas Nusa Mandiri Jakarta yang merupakan lulusan Ahli Madya Komputer dari Program Studi Sistem Informasi Universitas Bina Sarana Informatika Jakarta. 